\title{
Association of type 2 diabetes mellitus with the reduction of mandibular residual ridge among edentulous patients using panoramic radiographs
}

\author{
Osama Al-Jabrah
}

Department of Dentistry, King Hussein Medical Center, Royal Medical Services, Amman, Jordan.

Email: osamajabrah@hotmail.com

Received 15 April 2011; revised 30 May 2011; accepted 9 June 2011.

\begin{abstract}
Objective: To evaluate the association between type 2 diabetes mellitus and the reduction of mandibular residual ridge in completely edentulous patients wearing complete dentures and to investigate the effect of gender, age and years of edentulousness/ denture wearing on ridge resorption on both groups. Methods: Seventy-two ( 36 men and 36 women) with a mean age 63.5 years (range of 52 to 73 years) completely edentulous denture-wearing patients were included in this study. Of these, there were 40 patients with type 2 diabetes mellitus and 32 control subjects participated in the study. Resorption in the mandibular residual ridges was assessed by using the mental foramen and the inferior border of the mandible, as they appear in panoramic radiographs, as reference points using Wical and Swoope Analysis method. Measurements were performed using " $\mathrm{Di}$ jite” Digital Caliper. The amount of mandibular ridge resorption was calculated and correlated with type 2 diabetes mellitus and the results were compared with control group. Differences in gender, age and years of edentulousness were investigated. Statistical analysis was performed using SPSS (V11.0). A 2-sample t-test was used to evaluate the differences in mean values of mandibular ridge resorption between diabetics and controls. Level of significance was set at 0.05. Results: The mean mandibular residual ridge resorption of all participants is $8.0 \mathrm{~mm}(26.9 \%)$, diabetic group significantly $(P<0.01)$ had two times more resorption compared with control group (35.8\% versus $18.0 \%)$. Females recorded greater amount of resorption in diabetics $49.7 \%$ versus $21.8 \%(P<0.001)$ and in controls $22.3 \%$ versus $13.7 \%$, $(P<0.05)$ compared to males, respectively. There were no differences in both groups regarding the age of subjects and the length of time they have
\end{abstract}

been edentulous and years of denture wearing. The amount of mandibular residual ridge resorption was directly related to the number of years of edentulousness. Conclusion: Completely edentulous, denture-wearing diabetics, women in particular, are at more risk to have ridge resorption than "nondiabetic" subjects. Reduced mandibular height is directly related to years of edentulousness and denture wearing with greater amount of resorption among diabetics.

Keywords: Type 2 Diabetes Mellitus; Residual Ridge Resorption; Mandible; Mental Foramen; Edentulous; Complete Denture; Panoramic Radiology

\section{INTRODUCTION}

Residual ridge resorption (RRR) is a continuous process of alveolar bone loss, which is greater during the first few months after the tooth extraction than later, since it slows down with time after extraction [1-4]. The rate of resorption is supposed to be twice more pronounced in the mandible than in the maxilla during a period which follows teeth extraction and the ratio of 4:1 mandibular to maxillary resorption increases further [5]. The mandible seems to be the bone within the human skeleton that is most exposed to severe decrease in its height and mineral content as it is one of the primary source of the available calcium in the body [2].

The factors that contribute to RRR are still not completely elucidated. Some systemic factors that contribute to the RRR are: nutritional, hormonal imbalance, metabolic bone disease, some renal diseases, drug intake, postmenopausal hormonal disturbances in women, age, sex, etc [6,7]. Local factors that contribute to RRR are denture retention and stability, pressure applied to residual ridge through occlusal contacts, incorrect vertical or horizontal relation of the dentures, night-time wearing 
of dentures, balanced or non-balanced occlusion, duration of denture wearing, disuse, atrophy or reduced masticatory forces in denture wearers compared with agematched dentate subjects etc [8].

Osteoporosis is one of the most important clinical conditions facing the aging population due to the associated high incidence of RRR [9]. It has been found that severity of bone loss, in both osteoporosis and residual ridges, increases with the advance of age and favors the female sex for predisposition. Post menopausal women comprise most of the female edentulous population with severe RRR. The effect of menopause on the mandible was thought to be similar to the effect on the rest of the skeleton and therefore places the post menopausal women at a higher risk of becoming complete denture patients with severe RRR [10,11].

Diabetes mellitus (DM) is a chronic disease, which occurs when blood glucose concentration in body is in excess [12]. It is characterized by hyperglycemia and glucose intolerance [13]. The disorder is used to describe the increased concentration of glucose in the blood while glucose intolerance is associated with insulin resistance. There are mainly two types of DM; type 1 and type 2 diabetes. Type 1 diabetes (T1DM), previously known as insulin-dependent is characterized by a lack of insulin production. Type 2 diabetes (T2DM), formerly called non-insulin-dependent is caused by the body's ineffective use of insulin. It often results from excess body weight and physical inactivity. As a result of DM, it affects the blood circulations and is associated with many complications such as cardiovascular diseases, particularly heart attack and stroke [12,14]. Furthermore, it is found that DM also reduces healing of wounds [15], causes bone resorption and has been considered to contribute to failure in dental treatment [16].

Complete dentures (CDs) are widely used in restoration of completely edentulous dental arches [17]. The resulting shape and size of the residual ridge influence the degree of stability and retention of the denture and affect the amount of applied load [1]. Before considering prosthodontic treatment, both the quantity and quality of the bone must be assessed radiographically [18]. There is a gradual deterioration of body functions with age and any general systemic disability would make denture success uncertain. Further, people of the CDs age are likely to have contributing health problems which cause denture difficulties [19].

Panoramic radiographs (OPG) were utilized because they have certain advantages over intra-oral radiography. These include a greater area of hard and soft tissue and also the ability to visualize adjacent areas, thus allowing for a more accurate localization of the mental foramen (MF) in both the horizontal and vertical dimensions
[20,21].

The aim of the present study was to assess the amount of mandibular RRR in edentulous patients wearing CDs and to evaluate the relationship between RRR and T2DM, to compare the amount of resorption between diabetics and "nondiabetic" control subjects and to evaluate the effect of age, gender and years of edentulousness and CD-wearing on the amount of resorption.

\section{MATERIALS AND METHOD}

This study was carried out at the Prosthodontic Clinic, Department of Dentistry, Prince Rashid Bin Al-Hassan Hospital in Irbid, Jordan; over one year period from August 2010 to July 2011.

\subsection{Patients}

The original sample for the present study was selected from a general population of completely edentulous subjects who attended (or referred to) Prosthodontic clinic.

The study sample comprises seventy-two (36 (50.0\%) males and $36(50.0 \%)$ females) participants with a mean age $63.5( \pm 11.6)$ years (ranged between 52 and 73 years) completely edentulous patients were selected and accepted to participate in this study. Of these, there were 40 patients with type T2DM and 32 control subjects. All participants were CD wearers.

\subsection{Inclusion/Exclusion Criteria}

The selected subjects had not undergone prosthetic surgical procedures (i.e. sulcus deepening or ridge augmentation). They were completely edentulous with not less than one year post-tooth extraction period. All participants have been diabetics for 5 years or more.

\subsection{Measurements}

For each participant an OPG was taken using Orthoralix 9200 ${ }^{\circledR}$ (Gendex, SN: 5-1822514DP; IL, USA). Mandibular RRR was assessed by using the MF and the inferior border of the mandible, as they appear in OPGs, as reference points using Wical and Swoope Analysis method; in which the original height of the mandible is assumed to be 3 times the distance between the inferior border of the mandible to the lower border of the MF [22]. The amount of resorption $(\mathrm{R})$ from the original mandibular alveolar level to the measured level of the residual ridge $(\mathrm{L})$ was expressed as a percentage of the original height of the mandible (Figure 1).

The amount of resorption was calculated according to the formula: $\mathrm{R}=3 x-\mathrm{L}$, (where $\mathrm{R}$ : amount of mandibular RRR; $x$ : distance from inferior border of mandible to the lower border of MF; L: height of mandibular residual alveolar ridge). 


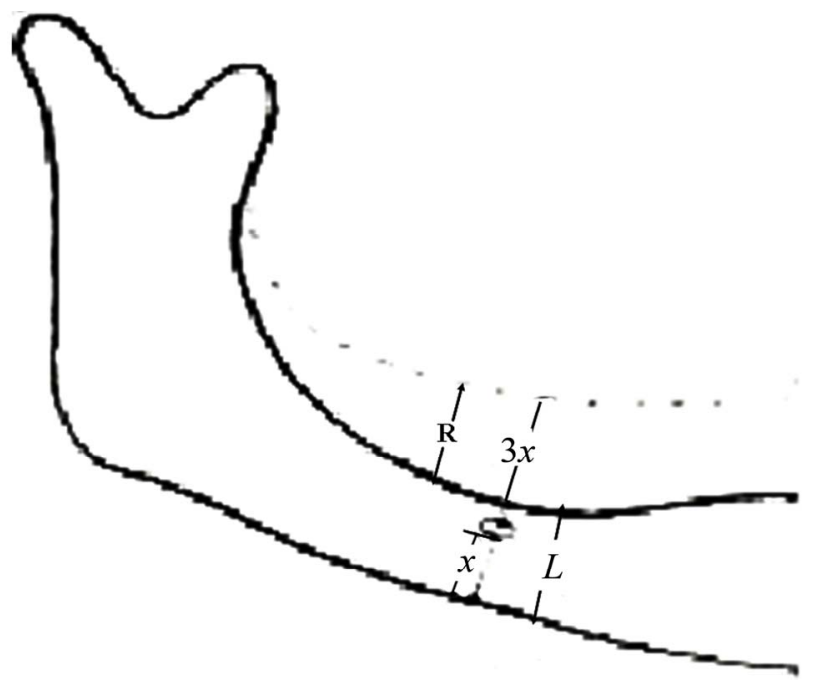

Figure 1. Wical and Swoope analysis method $(\mathrm{R}=3 x-\mathrm{L})$.

Measurements were performed using Dijite carbon fiber composite digital caliper (Guilin Digital Electronic Co., Ltd. Guangxi, China) to the nearest tenth of a millimetre for specific measured dimensions on each OPG. The caliper has two edges; external and internal (Figure 2); the external edges were used in the measurements.

The amount of mandibular RRR was calculated and correlated with T2DM, and with wearing CDs. The results were compared with those of non-diabetic (control) group. Gender and age differences were also investigated and correlated to DM and CD.

Measurements were performed on the right side, and they were repeated 3 times and the mean value and standard deviation were calculated for further analysis. Measuring gauge had a resolution of $0.1 \mathrm{~mm}$ and measured dimensions were recorded to this degree of accuracy.

\subsection{Statistical Analysis}

Statistical analysis was performed using Statistical Package for Social Sciences; Version 11 (SPSS-V11.0 Inc., Chicago, Ill., USA). A 2-sample t-test was used to evaluate the differences in mean values of mandibular RRR between DM and control groups of patients. Student's t-test was used to determine whether there were gender differences in the amount of RRR and DM. The Mann-Whitney U test was used to examine the differences in the duration of edentulousness between men and women.

Chi square analysis was used to study the association between CD wearing period and amount of RRR. Ninety-five percent confidence intervals about the mean were constructed for differences between DM and control group and male and female participants. Level of significance was set at 0.05 .

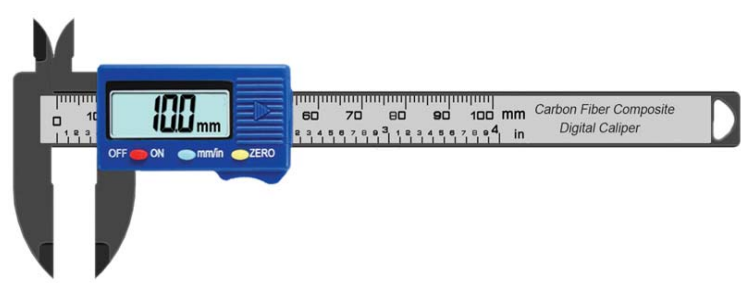

Figure 2. Dijiti carbon fiber composite digital caliper.

\section{RESULTS}

Variability and bias in measurements between right and left sides were assessed by re-measuring the height of mandible across the MF on 11 (15.3\%) randomly selected OPGs on the left side.

Paired Student's t-test was performed to unveil statistically significant deviation of measurements between right and left sides, (mean difference $0.065 \pm 0.13 \mathrm{~mm}$; P value $=0.92$ ). As there were strong Cronbach's coefficient and small mean difference between the two-side measurements, it was assumed that the right side measurements would be reliable.

The mean age of T2DM subjects was $63.8 \pm 6.7$ years, ranged between 55 and 73 years; and of control subjects was $61.6 \pm 7.4$ years, ranged between 52 and 69 years. The age and sex distribution of diabetic and control groups are shown in Table 1.

Table 2 shows that the amount of mandibular RRR in DM subjects is approximately twice as that in control group. The difference between groups was statistically significant $(\mathrm{p}<0.01$; two-sample t-test).

Gender differences between the two groups are shown in Table 3. Generally, results showed that females significantly have two times as resorption as males $(\mathrm{P}<$ $0.001)$. Statistically significant gender differences in mandibular RRR have been recorded in DM $(\mathrm{P}<0.001)$ and control $(\mathrm{P}<0.05)$ group.

Table 4 shows comparison of age, mandibular RRR, and years since edentulousness and/or wearing CDs between DM patients and controls. Statistically significant differences in mandibular RRR were recorded between the two groups. The DM group had approximately as twice as compared with the controls $(\mathrm{P}<0.01)$. However, there were no differences between the two groups in the mean age of subjects as well as in years of edentulousness/CD wearing.

Table 5 shows correlation of $\mathrm{CD}$ wearing duration with the amount of mandibular RRR between DM and control groups. It has been shown that RRR is directly proportional to period of edentulousness and $\mathrm{CD}$ wearing. The differences between the two groups were statistically significant among subjects who have been wearing CDs for 15 years or less $(\mathrm{P}<0.001)$ and also in those who have been edentulous for more than 15 years $(\mathrm{P}<0.05)$. 
Table 1. Distribution of study groups (diabetic and control) according to age and gender.

\begin{tabular}{cccccccc}
\hline \multirow{2}{*}{ Age range } & \multicolumn{2}{c}{ Diabetic group $(\mathrm{n}=40)$} & \multicolumn{2}{c}{ Control group $(\mathrm{n}=32)$} & \multicolumn{2}{c}{ Total $(\mathrm{n}=72)$} & \multirow{2}{*}{ Total } \\
\cline { 2 - 6 } & Male & Female & Male & Female & Male & Female & \\
\hline $50-54$ & 3 & 4 & 2 & 4 & 5 & 8 & 13 \\
$55-59$ & 4 & 4 & 3 & 4 & 7 & 8 & 15 \\
$60-64$ & 6 & 6 & 6 & 4 & 12 & 10 & 22 \\
$65-69$ & 5 & 4 & 3 & 3 & 8 & 7 & 15 \\
$70-74$ & 2 & 2 & 2 & 1 & 4 & 3 & 7 \\
Total & 20 & 20 & 16 & 16 & 36 & 36 & 72 \\
\hline
\end{tabular}

Table 2. Differences in the amount of mandibular ridge resorption between diabetic and control groups.

\begin{tabular}{ccccccccc}
\hline Group & IBM-MFx & $3 \mathrm{x}$ & $\mathrm{H}$ & $\mathrm{L}=3 \mathrm{x}-\mathrm{R}$ & $\mathrm{ROPG}$ & $\%=(\mathrm{R} / 3 \mathrm{x}) \times 100 \%$ & 2-sample t-test & $\mathrm{P}$ Value \\
\hline Diabetic & 10.0 & 29.9 & 19.9 & 19.4 & 10.5 & 35.8 & 1.99 & 0.0028 \\
Control & 10.5 & 31.5 & 21.0 & 26.6 & 5.5 & 18.0 & & $\mathrm{P}<0.01$ \\
Mean & 10.3 & 30.7 & 20.5 & 23.0 & 8.0 & 26.9 & & \\
\hline
\end{tabular}

IBM: inferior border of the mandible; $x$ : distance from IBM to lower border of MF; H: height of residual alveolar bone; R: amount of resorption; OPG: panoramic radiograph.

Table 3. Gender differences in the amount of mandibular ridge resorption between study groups groups.

\begin{tabular}{ccccccccccc}
\hline Group & & & IBM-MFx & $3 \mathrm{x}$ & $\begin{array}{c}\text { Height } \\
\text { above MF }\end{array}$ & $\mathrm{L}=3 \mathrm{x}-\mathrm{R}$ & $\mathrm{ROPG}$ & $\%=(\mathrm{R} / 3 \mathrm{x}) \times 100 \%$ & $\begin{array}{c}\text { Student's } \\
\mathrm{t} \text {-test }\end{array}$ & $\mathrm{p}$ Value \\
\hline \multirow{2}{*}{ Diabetic } & $\mathrm{M}$ & $\mathrm{n}=20$ & 11.5 & 34.5 & 23.0 & 26.2 & 8.3 & 21.8 & 2.28 & 0.00016 \\
& $\mathrm{~F}$ & $\mathrm{n}=20$ & 8.4 & 25.2 & 16.8 & 12.5 & 12.7 & 49.7 & $\mathrm{p}<0.001$ \\
Control & $\mathrm{M}$ & $\mathrm{n}=16$ & 11.9 & 35.7 & 23.8 & 30.8 & 4.9 & 13.7 & 1.63 & 0.022 \\
& $\mathrm{~F}$ & $\mathrm{n}=16$ & 9.1 & 27.3 & 18.2 & 22.3 & 6.1 & 22.3 & $\mathrm{p}<0.05$ \\
Total & $\mathrm{M}$ & $\mathrm{n}=36$ & 11.7 & 35.0 & 32.3 & 28.8 & 6.8 & 18.2 & 2.06 & 0.00056 \\
& $\mathrm{~F}$ & $\mathrm{n}=36$ & 8.7 & 26.1 & 17.6 & 16.8 & 9.8 & 37.5 & $\mathrm{p}<0.001$ \\
Mean & & & 10.2 & 30.6 & 25.0 & 22.8 & 8.4 & 27.9 & & \\
\hline
\end{tabular}

M: male; F: female; IBM: inferior border of the mandible; $\mathrm{x}$ distance from IBM to lower border of MF; H: height of residual alveolar bone; $\mathrm{R}$ : amount of resorption; OPG: panoramic radiograph.

Table 4. Comparison of age, mandibular residual ridge resorption, and years since edentulousness and/or wearing dentures between diabetic patients and controls.

\begin{tabular}{ccccc}
\hline & $\mathrm{n}$ & Age (Year) & $\begin{array}{c}\text { Mandibular residual ridge } \\
\text { resorption }(\mathrm{mm})\end{array}$ & $\begin{array}{c}\text { Edentulousness/Denture-wearing } \\
\text { (Years) }\end{array}$ \\
\hline Diabetic & 40 & $66.4 \pm 8.7$ & $10.5 \pm 2.1$ & $8.5 \pm 4.1$ \\
Control & 32 & $64.3 \pm 6.9$ & $5.5 \pm 2.6$ & $9.6 \pm 5.7$ \\
Mann-Whitney U test & & 0.26 & 0.0073 & 0.084 \\
P value & $\mathrm{NS}$ & $<0.01$ & $\mathrm{NS}$ \\
\hline
\end{tabular}

NS: Not significant.

Table 5. Correlation of duration of denture wearing with the amount of mandibular ridge resorption between study groups.

\begin{tabular}{|c|c|c|c|c|c|c|c|}
\hline \multirow{3}{*}{$\begin{array}{l}\text { Denture age } \\
\text { Years }\end{array}$} & \multicolumn{4}{|c|}{ Mandibular residual ridge resorption (in \%) } & \multirow{3}{*}{ Chi square test } & \multirow{3}{*}{$P$ value } & \multirow{3}{*}{ Level of significance } \\
\hline & \multicolumn{2}{|c|}{ Diabetic } & \multicolumn{2}{|c|}{ Control } & & & \\
\hline & $\mathrm{n}$ & $\%$ & $\mathrm{n}$ & $\%$ & & & \\
\hline$<3$ & 5 & 19.5 & 4 & 9.4 & 59.6 & 0.024 & $<0.001$ \\
\hline $3-5$ & 10 & 27.2 & 9 & 12.1 & 45.4 & 0.031 & $<0.001$ \\
\hline $5-9$ & 12 & 38.3 & 10 & 18.8 & 33.7 & 0.046 & $<0.001$ \\
\hline $10-14$ & 7 & 46.4 & 5 & 20.0 & 29.4 & 0.048 & $<0.001$ \\
\hline $15-19$ & 4 & 55.6 & 3 & 33.7 & 16.5 & 0.084 & $<0.05$ \\
\hline$>20$ & 2 & 68.7 & 1 & 41.5 & 12.2 & 0.093 & $<0.05$ \\
\hline
\end{tabular}




\section{DISCUSSION}

The study population consisted of all persons who attended or (referred to) the Prosthodontic Clinic, Division of Dentistry, Prince Rashid Hospital, Irbid, Jordan; for the provision of $\mathrm{CD}$ construction, or replacement or maintenance and correction of their existing old ones with new sets of dentures. The patients were interviewed in the clinic, and their OPGs were evaluated to determine the amount of RRR by using the MF as a reference point in the measurements so that the amount of mandibular RRR can be estimated and compared between DM subjects and controls.

Alveolar ridge resorption after teeth extraction is a chronic, progressive and cumulative disease of bone reconstruction. Extensive RRR is one of the many problems in prosthetic dentistry rehabilitation $[23,24]$. Many local and systemic factors are related with RRR. Local factors include conditions after teeth extraction (quality, quantity and shape of the residual ridge, muscle attachment, etc.), edentulousness, bite stress from the denture to the edentulous ridge. Systemic factors include patient's age, gender, $\mathrm{Ca}$ deficiency, $\mathrm{Ca}$ and $\mathrm{P}$ metabolism disorders, systemic osteoporosis and hormonal disturbances. All these factors together cause resorptive changes in the edentulous parts of the maxilla and mandible [25].

DM is a common disorder of carbohydrate metabolism through either decreased production of insulin or tissue resistance to the effects of insulin [26]. The risk for alveolar bone loss is greater, and bone loss progression more severe, for subjects with poorly-controlled T2DM compared to nondiabetic individuals or with better controlled diabetes [27]. T2DM was positively associated with greater risk for a change in bone score (compared to subjects without diabetes) [28]. These results suggest that poorer glycemic control leads to both an increased risk for alveolar bone loss and more severe progression over those without T2DM [29].

In this study it was found that the amount of mandibular RRR among T2DM subjects was higher than that among nondiabetic subjects. It has been reported that diabetic patients have a wide range of defects that delay the healing process and that increase their susceptibility to infection [30].

Furthermore, the prevalence of bone resorption among patients with diabetes tends to be greater than among the general population; this difference may be related to hyperglycemia in the former group [31].

Accursi [32] examined the impact of DM on the success of dental implants. He concluded that the diabetic patients were more likely to have greater loss in crestal bone levels around the implants than the nondiabetic patients. In addition, he also reported interesting soft- tissue and neurological complications in the diabetic group. He found that soft-tissue complications were similar in number in the diabetic and control groups; in both groups, these complications were mainly of a minor nature and resolved with improvement in oral hygiene.

In the present study, gender-related differences were recorded in both groups. Female subjects were shown to have more amount of mandibular RRR compared with their male counterparts. In addition, diabetic females suffered more resorption than the female controls. Most of the females in the present study were past the usual age for menopause, and this may explain the gender-related difference observed in this study. Previous studies have reported similar results [33,34]. Furthermore, experimental evidence has shown that estrogen depletion leads to a significant loss of bone mass in the edentulous mandible but not in the dentate mandible [35].

Xie et al. [36] have found that females have more alveolar RRR than males, while Atwood and Coy have presented a slightly higher rate in males [37]. The results of the present study have suggested that alveolar RRR is more noticeable in females. This phenomenon could be explained with the effect of the menopausal activity in women on the alveolar RRR.

Previous studies showed that women had reduced masticatory function compared with males, because women had greater amount of mandibular bone reduction which is associated with reduced cortical thickness [38], and resulted in reduction in bone height [39]. Conversely, some researchers have reported that it is not known, if mandibular bone loss observed in the edentulous mandible in association with estrogen deficiency [35], results from increased bone resorption alone or the combined effect of increased bone resorption and reduction in bone formation rate [40].

The amount of mandibular RRR was significantly correlated with the number of years subjects were edentulous, however, diabetic patients were shown to have more resorption when compared with control subjects. These findings are in agreement with previous studies [41-43].

MF landmark selected for the present study is commonly used for studies of mandibular bone as it is fairly reproducible [44-46]. The location of the MF relative to the inferior and superior borders of normal mandibles, as expressed by the mean ratio of total bone height to height of the foramen above the inferior border, appears to be consisted enough to justify its use as a reference point in clinical studies. Since the bone below MF constitutes a predictable proportion of the total bone height in the majority of normal subjects, and since this bone is not significantly affected by resorption until extreme 
atrophy occurs, its height may serve as the basis for estimating the original mandibular height in elderly subjects [22].

In this study, Wical and Swoope method was used to evaluate the amount of mandibular RRR [22]. Clinically, the lower edge of the MF appears to be a more useful reference mark in OPGs. Observing the distance from the inferior border of the mandible to the lower edge of $\mathrm{MF}$ and using the approximate ratio of 3:1 can help to estimate conveniently the original height of the mandible before resorption $[47,48]$.

The main objectives of preoperative assessment are to determine if there is sufficient bone in the alveolar ridge and to determine the precise position of the anatomical structures in order not to be damaged during surgery $[17,49]$.

OPG is a widely used technique because it has the advantage of providing, in a single film, the image of both jaws, with a relatively low radiation dose, in a short period of time, and at lower cost if compared to more sophisticated techniques [50]. This technique can offer information about the localization of anatomic structures and vertical bony dimensions. However, without knowing the magnification degree and the image distortion, mistakes in measurements may occur, in addition, OPG does not provide the buccolingual view of the bone [51].

As changes in the mandibular cortex can be detected on the OPG of patients with osteoporosis, it can be considered an important diagnostic tool [52] provided that diagnostic values are not lost due to projection errors resulting from disposition of the head [53]. OPGs can be used in determining the bone density, as a relationship between mandibular bone mineral density and the skeletal areas in evaluating osteoporosis has been shown [54].

Several studies have reported that OPGs are reproducible and accurate for the linear and angular measurements on mandibles [50,55]. It has been shown that reliability of the OPG technique for imaging of the mandible is highly dependent on head position $[36,56]$.

RRR has been measured using various radiographic techniques [22,23,37]. In the present study, OPGs were made by an experienced radiograph technician using the same panoramic unit. The technique for the measurement of the alveolar ridge resorption used was essentially the same as that described by Wical and Swoope. [22]. In a study of Wilding et al., in which the reliability of this technique was tested, it has been concluded that the use of this technique is sufficient to provide information about RRR of mandibular alveolar bone compared to a more complicated method [50].

The results of this study highlight on the association between DM and RRR in completely edentulous, CD wearers. It has been shown that women in particular, are at risk of RRR than nondiabetic subjects. For diabetics, effort should be taken to retain natural teeth to the longest time possible as the amount of resorption would increase with increasing CD wearing period. Basker et al. reported that the amount of bone resorption in edentulous area is eight times than that in dentate area in the same subject [57].

Further research on a larger sample and including other factors; such as other local and systemic factors, denture quality measures, general health status and wider age range may be needed before the results of this study can be applied on the general population.

\section{CONCLUSIONS}

Within the limitations of this study, the following conclusions can be withdrawn;

1) The mean amount of mandibular RRR in the whole sample is approximately $27 \%$.

2) Statistically significant difference $(\mathrm{P}<0.01)$ between the two study groups has been recorded, diabetic patients has two times greater amount of RRR compared to controls (35.8\% versus $18.0 \%$ ).

3) When compared with males, female subjects significantly have greater amount of RRR in both groups ( $P$ $<0.001)$. Significantly, diabetic females recorded the highest amount of RRR compared to diabetic males (49.7\% versus $21.8 \%$; $\mathrm{P}<0.001)$. Similar figures were recorded in control group $(22.3 \%$ versus $13.7 \%$; $\mathrm{P}<$ $0.05)$.

4) There were no differences in both groups regarding the age of the participants and the length of time they have been edentulous and years of CD wearing.

5) The amount of mandibular RRR was directly related to the number of years subjects were edentulous. Diabetic patients were significantly shown to have more resorption when compared with control subjects.

\section{REFERENCES}

[1] Atwood, D.A. (1988) Essentials of complete denture prosthodontics. 2nd Edition, PSG Pub Co, Littleton, 2238 .

[2] Wowern, N.V. (1988) Bone mineral content of mandibles: Normal reference values-rate of age-related bone loss. Calcified Tissue International, 43, 193-198. doi:10.1007/BF02555134

[3] Humphries, S., Devlin, H. and Worthington, H. (1989) A radiographic investigation into bone resorption of mandibular alveolar bone in elderly edentulous adults. Journal of Dentistry, 17, 94-96. doi:10.1016/0300-5712(89)90141-3

[4] Zarb, G.A., Bolender, C.L., Hickey, J.C. and Carlsson, G.E. (1990) Boucher's prosthodontics treatment for edentulous patients. 10th Edition, CV Mosby, St. Louis.

[5] Kovacic, I., Celebic, A., Zlataric, D.K., Stipetic, J. and Papic, M. (2003) Influence of body mass index and the 
time of edentulousness on the residual alveolar ridge resorption in complete denture wearers. Collegium Antropologicum, 27, 69-74.

[6] Lane, J.M. and Vigorita, V.J. (1984) Osteoporosis. Symposium on metabolic bone disease. Orthopedic Clinics of North America, 15, 711-728.

[7] Habets, L.L., Bras, J. and Borgmeyer-Hoelen, A.M. (1988) Mandibular atrophy and metabolic bone loss. International Journal of Oral and Maxillofacial Surgery, 17, 208-211. doi:10.1016/S0901-5027(88)80035-3

[8] Tallgren, A. (1970) Alveolar loss in denture wearers as related to facial morphology, Acta Odontologica Scandinavica, 28, 251-270. doi:10.3109/00016357009032033

[9] Violi, L.V. (1991) Significance of osteoporosis: A growing international health care problem. Calcified Tissue International, 49, 55-57.

[10] Ortman, L.F., Hausmann, E. and Dunford, R.G. (1989) Skeletal osteopenia and residual ridge resorption. Journal of Prosthetic Dentistry, 61, 321-325. doi:10.1016/0022-3913(89)90137-6

[11] Sahi, T., Alhava, E.M. and Tilvis, R. (1991) Prevention of osteoporosis. Calcified Tissue International, 49, 5355.

[12] Bianchi, C., Miccoli, R., Penno, G. and Del Prato, S. (2008) Primary prevention of cardiovascular disease in people with dysglycemia. Diabetes Care, 31, 208-214. doi: $10.2337 / \mathrm{dc} 08-\mathrm{s} 256$

[13] Fonseca, V.A. (2007) Identification and treatment of prediabetes to prevent progression to type 2 diabetes. $\mathrm{Cl}$ inical Cornerstone, 8, 10-20. doi:10.1016/S1098-3597(09)60004-1

[14] Aronson, D. (2008) Hyperglycemia and the pathobiology of diabetic complications. Advances in Cardiology, 45, 1-16. doi:10.1159/000115118

[15] Chaudhary, S.B., Liporace, F.A., Gandhi, A., Donley, B.G., Pinzur, M.S. and Lin, S.S. (2008) Complications of ankle fracture in patients with diabetes. Journal of the American Academy of Orthopaedic Surgeons, 16, 159170.

[16] Kotsovilis, S., Karoussis, I.K. and Fourmousis, I. (2006) A comprehensive and critical review of dental implant placement in diabetic animals and patients. Clinical Oral Implants Research, 17, 587-599. doi:10.1111/j.1600-0501.2005.01245.x

[17] Abraham, J.J. (1993) The role of diagnostic imaging in dental implantology. Radiologic Clinics of North America, 31, 163-180.

[18] Jacobs, R., Adriansens, A., Naert, I., Quirynen, M., Hermans, R. and Van Steenberghe, D. (1999) Predictability of reformatted computed tomography for pre-operative planning of endosseous implant. Dentomaxillofacial Radiology, 28, 37-41. doi:10.1038/sj.dmfr.4600403

[19] Setyaadmadja, A.T. (1969) Predictive prosthodontics. General health status and edentulousness. Journal of Prosthetic Dentistry, 21, 475-479. doi:10.1016/0022-3913(69)90067-5

[20] Leong, I.T., Slabbert, J.C.G. and Becker, P.J. (1992) The value of radiographic predictors of the rate of mandibular residual ridge resorption. Journal of Prosthetic Dentistry, 68, 69-73. doi:10.1016/0022-3913(92)90288-L

[21] Jacobs, R. and Van Steenberghe, D. (1997) Radiographic planning and assessment of endosseous oral implants.
Springer Verlag, Berlin.

[22] Wical, K.E. and Swoope, C.C. (1974) Studies of residual ridge resorption. Part I. Use of panoramic radiographs for evaluation of mandibular resorption. Journal of Prosthetic Dentistry, 32, 7-12. doi:10.1016/0022-3913(74)90093-6

[23] Karaagaçlioglu, L. and Ozkan, P. (1994) Changes in mandibular ridge height in relation to aging and length of edentulism period. The International Journal of Prosthodontics, 7, 368-371.

[24] Nissan, J., Barnea, E., Zeltzer, C. and Cardash, H.S. (2003) Relationship between the craniofacial complex and size of the resorbed mandible in complete denture wearers. Journal of Oral Rehabilitation, 30, 1173-1176. doi:10.1111/j.1365-2842.2003.01192.x

[25] Klemetti, E. and Kolmakow, S. (1997) Morphology of the mandibular cortex on panoramic radiographs as an indicator of bone quality. Dentomaxillofacial Radiology, 26, 22-25. doi:10.1038/sj.dmfr.4600203

[26] Mohammad, A.R., Alder, M. and McNally, M.A. (1996) A pilot study of panoramic film density at selected sites in the mandible to predict osteoporosis. The International Journal of Prosthodontics, 9, 290-294.

[27] Taylor, G.W., Burt, B.A., Becker, M.P., Genco, R.J. and Shlossman, M. (1998) Glycaemia control and alveolar bone loss progression in type 2 diabetes. Annals of $\mathrm{Pe}$ riodontology, 3, 3039-3043 doi:10.1902/annals.1998.3.1.30

[28] Watanabe, P.C.A., Farman, A., Watanabe, M.G.D.C. and Issa, J.P.M. (2008) Radiographic signals detection of systemic disease. Orthopantomographic radiography. International Journal of Morphology, 26, 915-926.

[29] Zlataric, D.K., Celebic, A. and Lazic, B. (2002) Resorptive changes of maxillary and mandibular bone structures in removable denture wearers. Acta Stomatologica $\mathrm{Cr}$ oatica, 36, 261-265.

[30] Devlin, H., Garland, H. and Sloan, P. (1996) Healing of tooth extraction sockets in experimental diabetes mellitus. Journal of Oral and Maxillofacial Surgery, 54, 10871091. doi:10.1016/S0278-2391(96)90166-4

[31] Mathiassen, B., Nielsen, S., Ditzel, J. and Rodbro, P. (1990) Long-term bone loss in insulin-dependent diabetes mellitus. Journal of Internal Medicine, 227, 325-327. doi:10.1111/j.1365-2796.1990.tb00167.x

[32] Accursi, GE. (2000) Treatment outcomes with osseointegrated Branemark implants in diabetic patients: A retrospective study. University of Toronto, Toronto.

[33] Elders, P.J.M., Netelenbos, J.C., Lips, P., Khoe, E., van Ginkel, F.C., Hulshof, F.A.M., et al. (1988) Accelerated vertebral bone loss in relation to menopause. A crosssectional study on lumber bone density in 286 women of 46 to 55 years of age. Bone and Mineral, 5, 11-19. doi:10.1016/0169-6009(88)90003-7

[34] Engel, M.B., Rosenberg, H.M., Jordan, S.L. and Holm, K. (1994) Radiological evaluation of bone status in the jaw and in the column in a group of women. Gerodontology, 11, 86-92. doi:10.1111/j.1741-2358.1994.tb00113.x

[35] Elsubeihi, E.S., Grynpas, M.D., Cheung, A., Zarb, G.A. and Heersche, J.N.M. (2001) The effect of ovariectomy on bone loss in the edentulous and dentate mandible. Bone, 28, 525-529.

[36] Xie, Q., Wolf, J. and Ainamo, A. (1997) Quantitative 
assessment of vertical heights of maxillary and mandibular bones in panoramic radiographs of elderly dentate and edentulous subjects. Acta Odontologica Scandinavica, 55, 155-161. doi:10.3109/00016359709115409

[37] Atwood, D.A. and Coy, W.A. (1971) Clinical, cephalometric, and densitometric study of reduction of residual ridges. Journal of Prosthetic Dentistry, 26, 280-295. doi:10.1016/0022-3913(71)90070-9

[38] Bresin, A., Kiliaridis, S. and Strid, K.G. (1999) Effect of masticatory function on the internal bone structure in the mandible of growing rat. European Journal of Oral Sciences, 107, 35-44. doi:10.1046/j.0909-8836.1999.eos107107.x

[39] Yamada, K. and Kimmel, D.B. (1991) The effect of dietary consistency on bone mass and turnover in the growing rat mandible. Archives of Oral Biology, 36, 129-138. doi:10.1016/0003-9969(91)90075-6

[40] Kingsmill, V.J. and Boyde, A. (1998) Variation in the apparent density of human mandibular bone with age and dental status. Journal of Anatomy, 192, 233-244. doi:10.1046/j.1469-7580.1998.19220233.x

[41] De Baat, C., Kalk W, van't Hof, M.A. (1993) Factors connected with alveolar bone resorption among institutionalized elderly people. Community Dentistry and Oral Epidemiology, 21, 317-320. doi:10.1111/j.1600-0528.1993.tb00783.x

[42] Bairam, L.R. and Miller, W.A. (1994) Mandible bone resorption as determined from panoramic radiographs in edentulous male individuals aged 25 to 80 years. Gerodontology, 11, 80-85. doi:10.1111/j.1741-2358.1994.tb00112.x

[43] Hirai, T., Ishijima, T. and Koshino, H. (1994) Age-related change of masticatory function in complete denture wearers: Evaluation by a sieving method with peanuts and a food intake questionnaire method. The International Journal of Prosthodontics, 7, 454-460.

[44] Apinhasmit, W., Methathrathip, D., Chompoopong, S. and Sangvichien, S. (2006) Mental foramen in Thais: An ana.tomical variation related to gender and side. Surgical and Radiologic Anatomy, 28, 529-533. doi:10.1007/s00276-006-0119-7

[45] Al-Khateeb, T., Hamasha, A.A. and Ababneh, K.T. (2007) Position of the mental foramen in a northern regional Jordanian population. Surgical and Radiologic Anatomy, 29, 231-237. doi:10.1007/s00276-007-0199-z

[46] Al Talabani, N., Gataa, I.S. and Jaff, K. (2008) Precise computer-based localization of the mental foramen on panoramic radiographs in a Kurdish population. Oral Radiology, 24, 59-63. doi:10.1007/s11282-008-0076-4

[47] Krajicek, D.D., Dooner. J. and Porter, K. (1984) Observations on the histologic features of the human edentulous ridge. Part III: Bone. Journal of Prosthetic Dentistry, 52, 836-843. doi:10.1016/S0022-3913(84)80015-3

[48] Zengingul, A., Eskimez, Ş., Değer, Y. and Kama, J. (2007) Tooth wears and dentoalveolar compensation of vertical high. Journal of Biotechnology, 21, 362-365.

[49] Frederiksen, N.L. (1995) Diagnostic imaging in dental implantology. Oral Surgery, Oral Medicine, Oral Pathology, Oral Radiology and Endodontology, 80, 540554. doi:10.1016/S1079-2104(05)80153-2

[50] Wilding, R.J.C., Levin, I. and Pepper, R. (1987) The use of panoramic radiographs to measure alveolar bone areas. Journal of Oral Rehabilitation, 14, 557-567. doi:10.1111/j.1365-2842.1987.tb00752.x

[51] Rockenbach, M.I.B., Sampaio, M.C.C., da Costa, L.J. and da Costa, N.P. (2003) Evaluation of mandibular implant sites: Correlation between panoramic and linear tomography. Brazilian Dental Journal, 14, 209-213. doi:10.1590/S0103-64402003000300013

[52] White, S.C., Taguchi, A., Kao, D., Wu, S., Service, S.K., Yoon, D., Suei, Y., Nakamoto, T. and Tanimoto, K. (2005) Clinical and panoramic predictors of femur bone mineral density. Osteoporosis International, 16, 339-346. doi:10.1007/s00198-004-1692-4

[53] Klemetti, E., Kolmakov, S. and Kröger, H. (1994) Pantomography in assessment of the osteoporosis risk group. Scandinavian Journal of Dental Research, 102, 68-72.

[54] Dutra, V., Yang, J., Devlin, H. and Susin, C. (2005) Radiomorphometric indices and their relation to gender, age, and dental status. Oral Surgery, Oral Medicine, Oral Pathology, Oral Radiology and Endodontology, 99, 479484. doi:10.1016/j.tripleo.2004.09.013

[55] Ceylan, G., Yanikoğlu, N., Yilmaz, A.B. and Ceylan, Y. (1998) Changes in the mandibular angle in the dentulous and edentulous states. Journal of Prosthetic Dentistry, 80, 680-684. doi:10.1016/S0022-3913(98)70055-1

[56] Xie, Q. and Ainamo, A. (2004) Correlation of gonial angle size with cortical thickness, height of the mandibular residual body, and duration of edentulism. Journal of Prosthetic Dentistry, 91, 477-482. doi:10.1016/j.prosdent.2004.02.020

[57] Basker, R.M, Davenport, J.C. and Tomlin, H.R. (1992) Prosthetic treatment of the edentulous patient. 3rd Edition, MacMillan Education LTD, London, 149-151. 